\title{
Recalibration of the auditory continuity illusion: sensory and decisional effects
}

Citation for published version (APA):

Riecke, L., Micheyl, C., Vanbussel, M., Schreiner, C. S., Mendelsohn, D., \& Formisano, E. (2011).

Recalibration of the auditory continuity illusion: sensory and decisional effects. Hearing Research, 277(12), 152-162. https://doi.org/10.1016/j.heares.2011.01.013

Document status and date:

Published: 01/07/2011

DOI:

10.1016/j.heares.2011.01.013

Document Version:

Publisher's PDF, also known as Version of record

Document license:

Taverne

Please check the document version of this publication:

- A submitted manuscript is the version of the article upon submission and before peer-review. There can be important differences between the submitted version and the official published version of record.

People interested in the research are advised to contact the author for the final version of the publication, or visit the DOI to the publisher's website.

- The final author version and the galley proof are versions of the publication after peer review.

- The final published version features the final layout of the paper including the volume, issue and page numbers.

Link to publication

\footnotetext{
General rights rights.

- You may freely distribute the URL identifying the publication in the public portal. please follow below link for the End User Agreement:

www.umlib.nl/taverne-license

Take down policy

If you believe that this document breaches copyright please contact us at:

repository@maastrichtuniversity.nl

providing details and we will investigate your claim.
}

Copyright and moral rights for the publications made accessible in the public portal are retained by the authors and/or other copyright owners and it is a condition of accessing publications that users recognise and abide by the legal requirements associated with these

- Users may download and print one copy of any publication from the public portal for the purpose of private study or research.

- You may not further distribute the material or use it for any profit-making activity or commercial gain

If the publication is distributed under the terms of Article $25 \mathrm{fa}$ of the Dutch Copyright Act, indicated by the "Taverne" license above, 
Research paper

\title{
Recalibration of the auditory continuity illusion: Sensory and decisional effects
}

\author{
Lars Riecke ${ }^{\mathrm{a}, *}$, Christophe Micheyl $^{\mathrm{b}}$, Mieke Vanbussel ${ }^{\mathrm{a}}$, Claudia S. Schreiner ${ }^{\mathrm{c}}$, Daniel Mendelsohn ${ }^{\mathrm{d}}$, \\ Elia Formisano ${ }^{a}$ \\ ${ }^{\text {a }}$ Faculty of Psychology and Neuroscience, Maastricht University, Universiteitssingel 40, Maastricht, The Netherlands \\ ${ }^{\mathrm{b}}$ Department of Psychology, University of Minnesota, USA \\ ${ }^{\mathrm{c}}$ Institute of Neuroscience and Medicine, Research Centre Jülich, Germany \\ ${ }^{\mathrm{d}}$ Schulich School of Medicine and Dentistry, The University of Western Ontario, Canada
}

\section{A R T I C L E I N F O}

\section{Article history:}

Received 6 May 2010

Received in revised form

17 January 2011

Accepted 19 January 2011

Available online 27 January 2011

\begin{abstract}
A B S T R A C T
An interrupted sound can be perceived as continuous when noise masks the interruption, creating an illusion of continuity. Recent findings have shown that adaptor sounds preceding an ambiguous target sound can influence listeners' rating of target continuity. However, it remains unclear whether these aftereffects on perceived continuity influence sensory processes, decisional processes (i.e., criterion shifts), or both. The present study addressed this question. Results show that the target sound was more likely to be rated as 'continuous' when preceded by adaptors that were perceived as clearly discontinuous than when it was preceded by adaptors that were heard (illusorily or veridically) as continuous. Detection-theory analyses indicated that these contrastive aftereffects reflect a combination of sensory and decisional processes. The contrastive sensory aftereffect persisted even when adaptors and targets were presented to opposite ears, suggesting a neural origin in structures that receive binaural inputs. Finally, physically identical but perceptually ambiguous adaptors that were rated as 'continuous' induced more reports of target continuity than adaptors that were rated as 'discontinuous'. This assimilative aftereffect was purely decisional. These findings confirm that judgments of auditory continuity can be influenced by preceding events, and reveal that these aftereffects have both sensory and decisional components.
\end{abstract}

(c) 2011 Elsevier B.V. All rights reserved.

\section{Introduction}

In natural environments, sounds of interest are often masked momentarily by extraneous sounds, such as noise. Nevertheless, under some circumstances, listeners can still hear a target sound that is briefly interrupted by noise as 'continuing through' the noise. Remarkably, this may occur even when the target is physically interrupted, as long as the noise effectively masks the interruption (Houtgast, 1972; Warren et al., 1972). Psychophysical studies have revealed that this auditory continuity illusion occurs with various kinds of sounds, including tones (e.g., Ciocca and Bregman, 1987; Miller and Licklider, 1950; Thurlow, 1957) and speech (e.g., Bashford and Warren, 1987; Verschuure and Brocaar, 1983; Warren, 1970) (for reviews, see Bregman, 1990; Warren, 1999). Behavioral animal studies have further indicated that the phenomenon is experienced also by birds (Braaten and Leary, 1999; Seeba and Klump, 2009), cats (Sugita, 1997), and monkeys (Miller et al., 2001; Petkov et al., 2003).

\footnotetext{
* Corresponding author.

E-mail address: l.riecke@maastrichtuniversity.nl (L. Riecke).
}

Neurophysiological studies have investigated the neural basis of the phenomenon at the level of the thalamus (Schreiner, 1980) and of the auditory cortex (Heinrich et al., 2008; Micheyl et al., 2003; Petkov et al., 2007; Riecke et al., 2007, 2009a; Shahin et al., 2009; Sivonen et al., 2006; Sugita, 1997).

Most previous studies of the continuity illusion have not considered the possible role of sequential effects of prior auditory stimuli on the target sound, although such 'aftereffects' are well described in the literature for other auditory phenomena. For example, psychophysical studies have shown that prior adaptor stimuli can induce changes in behavioral thresholds for detecting and/or discriminating auditory features such as intensity or loudness (e.g., Mapes-Riordan and Yost, 1999; Marks, 1993; Scharf et al., 2002), amplitude- or frequencymodulation (e.g., Green and Kay, 1974; Tansley and Suffield, 1983; Wakefield and Viemeister, 1984), relative frequency (Schellenberg and Trehub, 1994), location (e.g., Frissen et al., 2003, 2005; Phillips and Hall, 2005), phonemic category (e.g., Eimas and Corbit, 1973; Sawusch and Jusczyk, 1981; Simon and Studdert-Kennedy, 1978), voice gender (Schweinberger et al., 2008), and the number of perceived streams (e.g., Bregman, 1978; Snyder et al., 2009a, 2008). Several of these psychophysical findings are paralleled by recent 
neurophysiological studies showing that prior acoustic input can induce rapid changes in the responses of neurons in the central auditory system (e.g., Bartlett and Wang, 2005; Brosch and Schreiner, 1997; Micheyl et al., 2005; Sekuler and Blake, 1994; Ulanovsky et al., 2003, 2004; Werner-Reiss et al., 2006). Remarkably, some of these changes in neural response may persist for a few seconds or more (e.g., Condon and Weinberger, 1991; Malone et al., 2002; Ulanovsky et al., 2003, 2004; Werner-Reiss et al., 2006).

Inspired by these previous studies, a recent study of the continuity illusion has investigated whether prior adaptor stimuli influence listeners' ratings of perceived continuity (Riecke et al., $2009 b)$. This study used as adaptor stimuli a tone that alternated with noise bursts. The adaptors were rated illusorily as continuous when the signal-to-noise ratio (SNR) was low (i.e., when the noise masked the gaps in the tone), and they were rated correctly as discontinuous when the SNR was high. The target stimulus was identical to the adaptor stimuli, except that the SNR was adjusted in such a way that the continuity of the target was ambiguous. The results revealed that listeners were more likely to judge the ambiguous target as continuous when it was presented after adaptors that were rated discontinuous than after adaptors that were rated continuous.

However, it is unknown whether this 'contrastive' aftereffect of the adaptors is sensory or decisional in nature: The aftereffect might alter the perception of continuity (sensory aftereffect) or the criteria applied to rate continuity (decisional aftereffect). The aftereffect might further be due to the sensation evoked by the adaptors (sensory factors) or listeners' categorization of the adaptors as either 'continuous' or 'discontinuous' (decisional factors). In addition, it needs to be investigated in more detail at which processing stage(s) in the auditory system these aftereffects originate.

Here, we addressed these unresolved issues in three psychophysical experiments. We studied listeners' continuity ratings of interrupted and uninterrupted targets (stimuli with an ambiguous SNR) as a function of different adaptors (stimuli with low, high, or ambiguous SNR). The ratings were analyzed in terms of sensitivity $\left(d^{\prime}\right)$ and decision criterion (C) (Green and Swets, 1966; Macmillan and Creelman, 1991), which allowed us to distinguish between sensory and decisional aftereffects (for similar applications of signal detection theory [SDT] in studies of the continuity illusion, see Bennett et al., 1984; Kluender and Jenison, 1992; Samuel, 1981). The aftereffects of physically identical ambiguous adaptors were further compared to the aftereffects of physically different unambiguous adaptors, which allowed us to distinguish between sensory and decisional factors. In addition, the adaptor and target stimuli were presented either to the same ear or to opposite ears, which allowed us to investigate at which auditory processing stages the aftereffects may originate.

\section{Materials and methods}

\subsection{Participants}

Thirty eight volunteers ( 26 females) between 19 and 57 years old (mean: 25) with no reported hearing problems participated in the study after giving informed consent. Three different groups of listeners $(N=14,14,17)$ participated in experiment 1,2 , and 3 (respectively), including three listeners who participated in both experiments 2 and 3, and two other listeners (authors M.V. and L.R.) who participated in all experiments. Except for the latter two, all participants were uninformed about the study background and received payment for their participation. As shown in supplemental Figures S1 and S2, excluding the data of the two non-naïve participants and the two oldest participants (aged 57 and 39) from the analyses did not change the overall results reported below.

\subsection{Stimuli}

The same stimuli were used as in Riecke et al. (2009b). These stimuli were comprised of a frequency sweep, which was either uninterrupted or periodically interrupted by noise (Fig. 1A). The sweep was obtained by multiplying the instantaneous frequency of a tone by a logarithmic function. The frequency of the sweep spanned a range from 1 to $3 \mathrm{kHz}$ over the course of the 5-s stimulus duration. The noise was obtained by band-pass filtering broadband Gaussian noise between 0.9 and $3.6 \mathrm{kHz}$ (3-dB cutoff frequencies; finite impulse response filter). The interrupted sweep was created by modulating the amplitude of the tone with a square wave function (500-ms period; $50 \%$ duty cycle), and filling the $250-\mathrm{ms}$ gaps with the filtered noise. All amplitude onsets and offsets were linearly ramped with 25-ms rise-fall times in such a way that the midpoints of the tone off-ramps coincided with the midpoints of the noise on-ramps, and vice versa. The amplitude of the tone remained constant at $60 \mathrm{~dB}$ sound pressure level across all three experiments. The amplitude of the noise was adjusted relative to the amplitude of the tone (i.e., the SNR was adjusted) to produce a continuity illusion in some conditions, and not in other conditions (see Task and design).

\subsection{Apparatus}

Stimuli were sampled at $44.1 \mathrm{kHz}$ with 16 bit resolution using Matlab 7.0.1 (MathWorks Inc., Natick, MA). They were presented diotically (experiments 1 and 3 ) or monotically (experiment 2) via headphones (HMD 25-1, Sennheiser electronic, Wedemark, Germany) in a sound-attenuated chamber using Presentation 9.30 software (Neurobehavioral Systems, Inc., Albany, CA, USA) and a Creative Sound Blaster Audigy 2ZS sound card (Creative Technology, Ltd., Singapore).

\subsection{Task and design}

Participants performed a modified yes-no task. They were given written instructions to attend to the tone, to ignore the noise, and to judge the overall continuity of the tone after each stimulus by pressing one of two buttons (labeled as 'mostly continuous' and 'mostly discontinuous'). Judgments had to be given within a 200ms response interval that was indicated by a visual cross turning green at stimulus offset (Fig. 1B).

Before the main experiment, participants' ability to perform the task and participants' perception of the interrupted tone were assessed using approximately 25 training trials. Individual thresholds for the continuity illusion were estimated by adjusting the SNR using a method of limits (Fechner, 1960). The measured thresholds corresponded to the $50 \%$-point on the psychometric functions. In the main experiment, these thresholds were used to create perceptually ambiguous stimuli comprising the interrupted tone, i.e., interrupted target stimuli that were approximately equally likely to be judged as 'continuous' or 'discontinuous' (Fig. 1C). In addition, stimuli comprising the uninterrupted tone were created; these uninterrupted target stimuli were physically identical to the interrupted target stimuli (same SNR), except that the tone was uninterrupted (Fig. 1C). On average, the SNR-threshold for the continuity illusion that was used for the target stimuli in the three experiments was equal to $-6.8 \pm 3.4 \mathrm{~dB}$ (mean \pm standard deviation [SD] across all listeners).

On each trial, the interrupted or uninterrupted target stimulus was presented (with equal probability), preceded by two presentations of one adaptor stimulus (defined in the next section; Fig. 1B). All stimuli were separated by a response interval; responses that fell within this interval or slightly outlasted it were considered as valid, whereas trials comprising no response or a clearly delayed response 

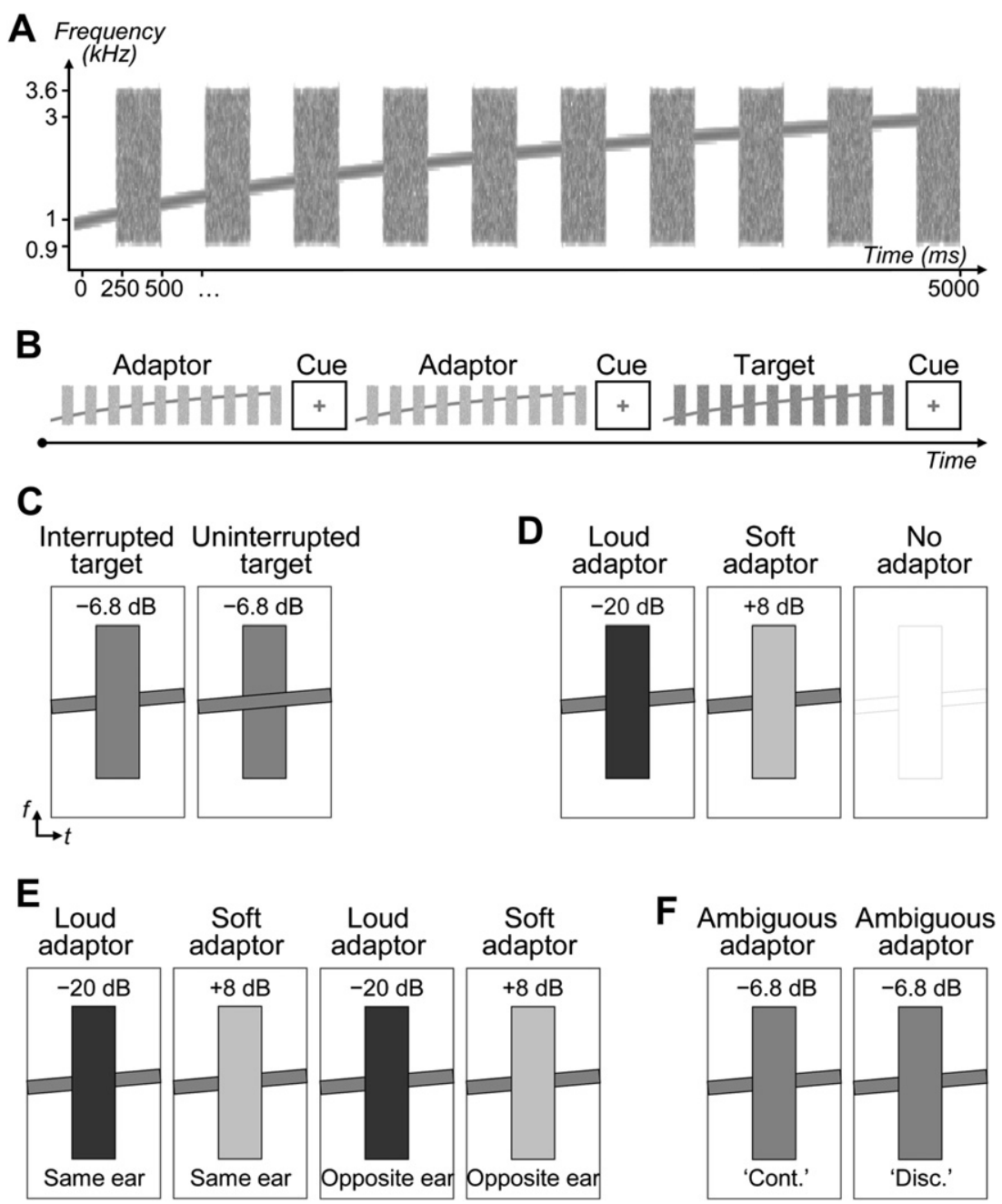

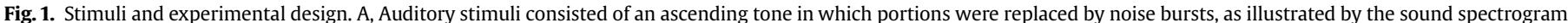

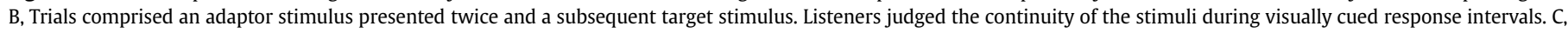

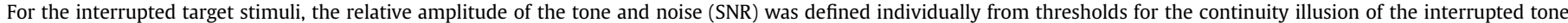

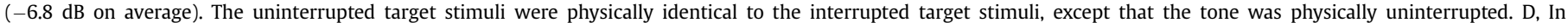

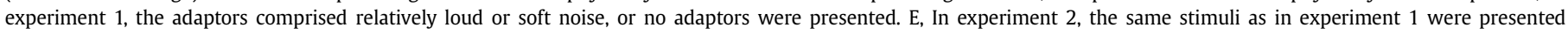

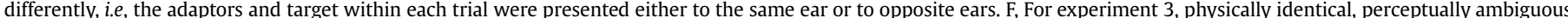

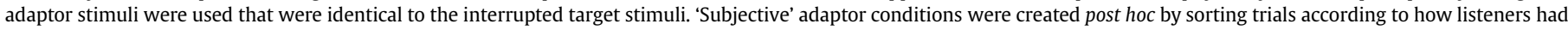
judged the ambiguous adaptors (i.e., as either continuous ['cont.'] or discontinuous ['disc.']).

were excluded from further analysis. Trials were counterbalanced and presented in individually randomized blocks. Five, four, and six blocks (block duration: approximately five, eight, and $7 \mathrm{~min}$ ) were presented during experiments 1,2 , and 3, respectively. Listeners were permitted to take breaks between blocks. The local ethics committee approved the study procedures.

\subsubsection{Design of experiment 1}

In experiment 1, two adaptor stimuli comprising either soft noise (soft adaptors, SNR $=+8 \mathrm{~dB}$ ) or loud noise (loud adaptors, $\mathrm{SNR}=-20 \mathrm{~dB}$ ) were presented prior to the interrupted or uninterrupted target stimulus. Based on earlier findings (Riecke et al., $2009 \mathrm{~b}$ ), the soft adaptors were expected to be rated as clearly discontinuous and bias the rating of the subsequent ambiguous target toward continuity, and vice versa for the loud adaptors. The aim of experiment 1 was to replicate these previous findings, and to determine whether the aftereffects of the adaptors on listeners' continuity ratings of the target reflect sensory or decisional aftereffects (see Introduction). A baseline no-adaptor condition in which the adaptors were replaced by silent intervals of the same duration as the adaptors was also tested. Each of the three adaptor conditions (Fig. 1D) was presented 30 times to each listener.

\subsubsection{Design of experiment 2}

The aim of experiment 2 was to investigate whether the previously observed aftereffects 'transfer' across the two ears. The same stimuli were used as in experiment 1 , but they were presented differently, i.e., adaptors and target within each trial were presented either to the same ear, or to opposite ears. This variation in the presentation mode allowed us to test whether the adaptors exerted aftereffects that were lateralized to the adapted ear or the nonadapted ear. Potentially confounding effects due to left- $v$ s. right-ear differences were avoided by counterbalancing the same-ear conditions and the opposite-ear conditions across the left and right ear. Each of the four adaptor conditions (Fig. 1E) was presented 32 times to each listener.

\subsubsection{Design of experiment 3}

The aim of experiment 3 was to determine the extent to which the previously observed aftereffects are induced by sensory or decisional 
factors of the adaptors (see Introduction). The design was similar to that of experiment 1 , except that all adaptor stimuli were identical to the interrupted target stimuli; thus, these adaptor stimuli were physically identical and perceptually ambiguous. Listeners' judgments of these perceptually ambiguous adaptors were used to separate trials post hoc into two groups which are referred to as subjective adaptor conditions: the 'continuous' adaptor condition included only trials on which listeners had reported the ambiguous adaptor stimulus as 'continuous', whereas the 'discontinuous' adaptor condition included only trials on which listeners had reported the same ambiguous adaptor stimulus as 'discontinuous' (Fig. 1F; for details see Statistical analysis). To make the two subjective adaptor conditions about equally likely, trials were immediately preceded by a perceptually unambiguous stimulus comprising either low SNR or high SNR with equal probability (the same stimuli referred to as 'adaptors' in experiment 1) and the response interval. This pre-adaptor stimulus served to bias the perception of the subsequent adaptor stimuli toward either veridical discontinuity percepts or continuity illusions. Each of these two trial types was presented 60 times to each listener.

\subsection{Statistical analysis}

To estimate listeners' sensitivity and decision criterion, $d^{\prime}$ and $C$ were computed as follows. Listeners' reports of the interrupted target as 'continuous' were considered as false alarms (FAs), whereas reports of the uninterrupted target as 'continuous' were labeled as hits. Following SDT (Green and Swets, 1966; Macmillan and Creelman, 1991), it was presumed that listeners' sensory noise levels were randomly distributed across trials and that this noise contributed additively and independently to the sensory representations of the different target stimuli. Hit and FA rates were transformed into $z$ scores using the inverse-cumulative standardnormal distribution. A constant of 0.5 was added to all response counts to enable $z$-transformation for ceiling cases, i.e., where rates of zero or one were measured (Brown and White, 2005). The resulting $z$ scores were then used to compute $d^{\prime}$ and $C$. This was done separately for each listener. In this model, $d^{\prime}$ reflects the sensitivity for detecting the continuity illusion, whereas $C$ reflects the decision criterion relative to that of an unbiased maximumlikelihood listener (a $C$-value of zero corresponds to the criterion value of an unbiased listener).

To assess the significance of the aftereffects of the adaptors on FA rates, hit rates, $d^{\prime}$, and $C$, each of these measures was compared statistically across the adaptor conditions, using SPSS 15.0 (SPSS inc., Baltimore, MD, USA). Group data exploration using Kolmogorov-Smirnov tests revealed that in most conditions the distributions of these measures did not diverge significantly from normality. Therefore, all statistical analyses were performed using parametric tests as follows. For repeated measures, ANOVAs and two-tailed paired $t$-tests were used, whereas for independent measures (group comparisons across experiments), two-tailed independent samples $t$-tests were used. To avoid inflated type-I error probabilities caused by multiple comparisons, all probability values obtained from a given sample population were corrected using the false-discovery rate (FDR; Benjamini and Hochberg, 1995). Only such FDR-corrected values are reported (see Results section) and a significance criterion $\alpha=0.05$ was used.

In the statistical analyses of experiment 3 , two different datasets were considered. The first dataset was specified by sorting trials according to listeners' judgments of the second subjective adaptor (i.e., the ambiguous stimulus that immediately preceded the target stimulus). Data from four listeners were discarded due to an insufficient number of samples (less than 15 repetitions in a subjective adaptor condition). For each of the remaining 13 listeners, the subjective adaptor conditions were counterbalanced by rejecting random trials from the condition that was reported more frequently, resulting in $42 \pm 15$ repetitions (mean \pm SD across listeners) of each condition. The second dataset was specified by considering only the trials on which listeners had given identical judgments of the first and second subjective adaptor (i.e., the two ambiguous stimuli that immediately preceded the target stimulus). Compared to the first dataset, this second dataset comprised trials with longer adaptation intervals that matched the length of the adaptation intervals in experiments 1 and 2. Furthermore, the second dataset comprised data from only ten listeners, each including $27 \pm 12$ repetitions (mean \pm SD across listeners) of each condition.

\section{Results}

In all experiments, FA rates were significantly higher for the loud adaptor ( $86.6 \%$ on average) than for the soft adaptor (3.1\% on average) (all $t_{13}>10.46, P<0.0000002$; Fig. 2 ). This indicates that the loud adaptor was judged as 'continuous' far more often than the soft adaptor, as expected based on previous results (Riecke et al., 2009b).

\subsection{Experiment 1}

Analysis for sensory aftereffects in experiment 1 revealed that the measure of sensitivity, $d^{\prime}$, varied significantly across the adaptor conditions $\left(F_{2,12}=7.19, P<0.02\right.$; Fig. $\left.3 \mathrm{~A}\right)$. Significantly smaller $d^{\prime}$-values were observed following soft adaptors than following loud adaptors $\left(t_{13}=2.73, P<0.03\right)$ or following no adaptors
A
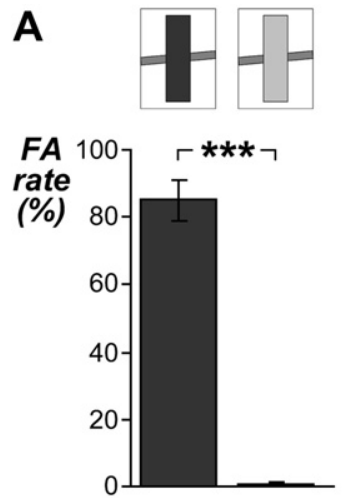

B
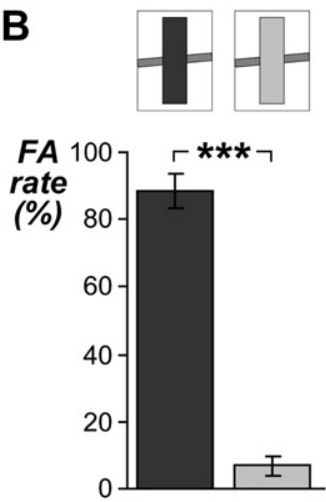

C
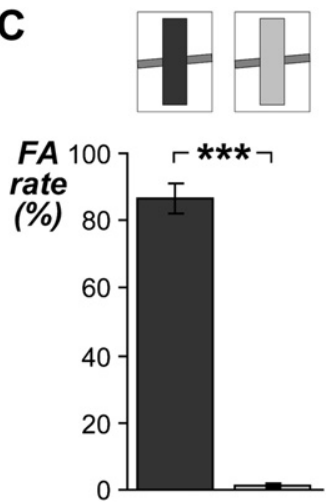

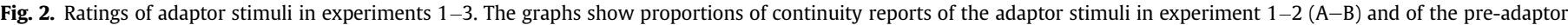

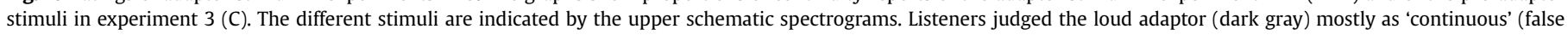
alarm [FA]) and the soft adaptor (light gray) mostly as 'discontinuous'. All graphs show means \pm SE across listeners. $* * * P<0.0005$. 
A

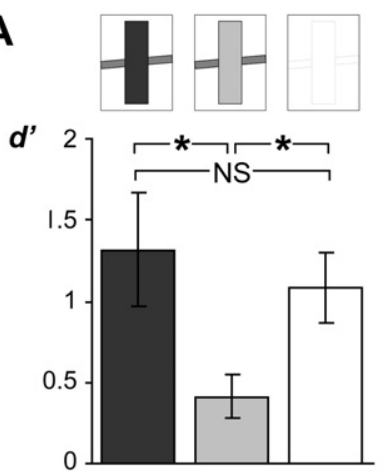

C

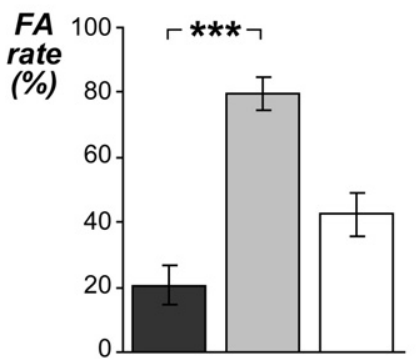

B

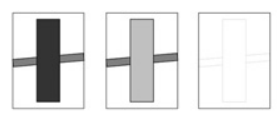

C 1.57 1.

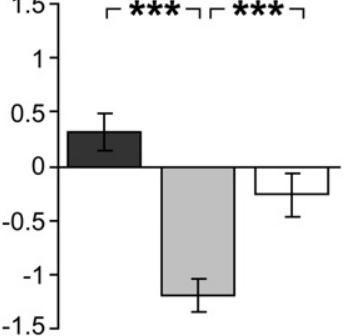

D

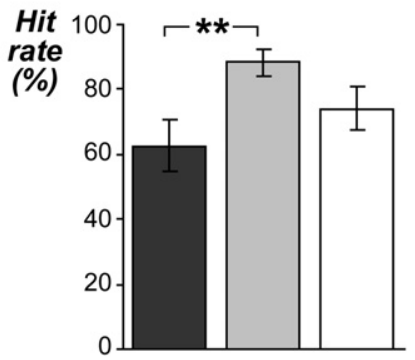

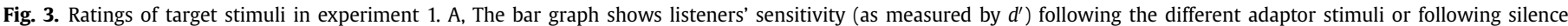

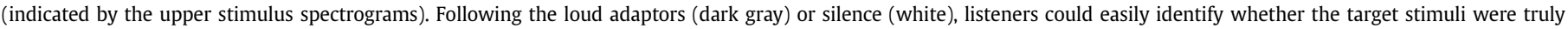

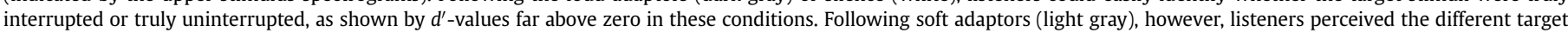

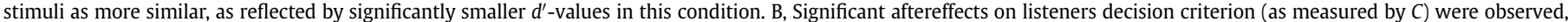

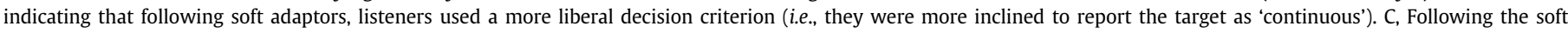

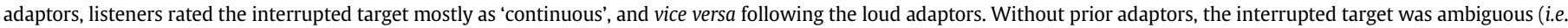

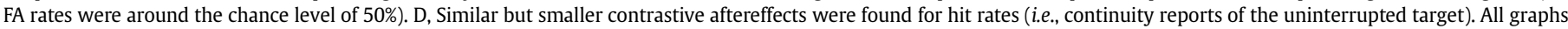
show means \pm SE across listeners. ${ }^{*},{ }^{* *},{ }^{* *}: P<0.05,0.005,0.0005 ;$ NS: not significant.

$\left(t_{13}=3.76, P<0.01\right)$. No significant difference was observed following loud adaptors compared to following no adaptors $\left(t_{13}=0.79, P=0.4\right)$. Since $d^{\prime}$ was derived from comparing ratings of sounds that evoke illusory continuity vs. ratings of sounds that evoke veridical continuity, the smaller values of $d^{\prime}$ indicate that listeners perceived illusory continuity and veridical continuity as rather similar. More specifically, the smallest values of $d^{\prime}$ in the softadaptor condition indicate that after these soft adaptors, listeners had most difficulty in identifying whether targets were truly interrupted or truly uninterrupted.

Analysis for decisional aftereffects revealed that the measure of decision criterion, $C$, also varied significantly across the adaptor conditions $\left(F_{2,12}=31.49, P<0.00003\right.$; Fig. 3B). Significantly smaller values of $C$ were observed following soft adaptors than following loud adaptors $\left(t_{13}=8.12, P<0.000008\right)$ or following no adaptors $\left(t_{13}=6.05, P<0.00005\right)$. Only following the soft adaptors, the values of $C$ differed significantly from zero (mean: $-1.19 ; t_{13}=7.44$, $P<0.00001$ ), the value corresponding to an unbiased maximumlikelihood listener. This indicates that after soft adaptors, listeners used a more liberal decision criterion (i.e., they were more inclined to report the target as continuous).

Analysis of FA rates revealed that the interrupted target was judged as 'continuous' more often following the soft adaptors than following the loud adaptors ( $t_{13}=7.40, P<0.00003$; Fig. $3 C$ ). This finding of a contrastive aftereffect replicates previous results (Riecke et al., 2009b). Similar results were obtained from analysis of hit rates, showing that also the uninterrupted target was judged as 'continuous' more often following the soft adaptors than following the loud adaptors $\left(t_{13}=4.21, P<0.002\right.$; Fig. $\left.3 \mathrm{D}\right)$. This aftereffect was smaller than the aftereffect observed for the interrupted target $\left(t_{13}=3.34\right.$, $P<0.006)$. Moreover, the uninterrupted target was generally judged as 'continuous' more often than the interrupted target $\left(t_{13}=5.32\right.$, $P<0.0003)$. Nonetheless, the aftereffects for interrupted and uninterrupted targets were qualitatively similar (i.e., of the same direction), being contrastive in both cases (Fig. 3C and D). In sum, the adaptors induced a sensory aftereffect and a decisional aftereffect (see previous sections on $d^{\prime}$ and $C$ ) which were reflected in contrastive changes in listeners' continuity ratings.

Additional analyses revealed that following the adaptor stimuli, FA rates were significantly different from $50 \%$ indicating that listeners performed beyond chance level when rating the interrupted target (all $t_{13}>4.87, P<0.0005$ ). In contrast, the FA rates measured in the no-adaptor condition were not significantly different from $50 \%\left(t_{13}=1.13, P=0.3\right)$, indicating that after $10 \mathrm{~s}$ of no adaptors (i.e., silence), listeners were indecisive about the continuity of the interrupted target. Statistical results from comparisons across the adaptor conditions are summarized in Fig. 3 (and in Figs. 4 and 5 for experiments 2 and 3; see the next two sections).

\subsection{Experiment 2}

Data analyses for experiment 2 confirmed the overall results of experiment 1 . As before, significantly smaller values of $d^{\prime}$ were observed following soft adaptors than following loud adaptors (Fig. 4A). This sensory aftereffect (i.e., the difference in $d^{\prime}$-values across the adaptor conditions) was found when the adaptors and interrupted target were presented to opposite ears $\left(t_{13}=2.76\right.$, $P<0.05)$ and a consistent trend was observed when they were presented to the same ear $\left(t_{13}=2.16, P<0.08\right)$. The aftereffect further did not differ significantly between these two presentation modes $\left(t_{13}=0.65, P=0.5\right)$. 
As in experiment 1 , values of $C$ varied significantly across the adaptor conditions; this was the case in the same-ear condition $\left(t_{13}=3.09, P<0.02\right)$ and also in the opposite-ear condition $\left(t_{13}=3.77\right.$, $P<0.008$; Fig. 4B). This decisional aftereffect (i.e., the difference in $C$-values across the adaptor conditions) further was significantly larger in the opposite-ear condition than in the same-ear condition $\left(t_{13}=2.47, P<0.03\right)$.

As in experiment 1 , the interrupted target was judged as 'continuous' more often following the soft adaptors than following the loud adaptors (see FA rates in Fig. 4C). This contrastive aftereffect was found for both the same-ear condition $\left(t_{13}=2.97, P<0.02\right)$, and the opposite-ear condition $\left(t_{13}=4.03, P<0.005\right)$. This aftereffect (i.e., the difference in FA rates across the adaptor conditions) further differed significantly between the two presentation modes $\left(t_{13}=2.40, P<0.04\right)$, which may be explained by the observed shift in the decision criterion (see section 3.1 on $C$ ). Qualitatively similar results were observed for the uninterrupted target (see hit rates in Fig. 4D). However, for the uninterrupted target, the aftereffect reached statistical significance only for the opposite-ear condition $\left(t_{13}=2.75, P<0.05\right)$, not for the same-ear condition $\left(t_{13}=1.55\right.$, $P=0.1$ ). Furthermore, these trends did not differ significantly across the two presentation modes $\left(t_{13}=1.89, P=0.1\right)$.

In sum, the results from experiment 2 confirm those of experiment 1 . In addition, they reveal that the contrastive sensory aftereffect did not depend crucially on whether the adaptors and target were presented to the same ear or to opposite ears.

\subsection{Experiment 3}

The aftereffects that were found in experiment 3 differed strongly from the aftereffects that were observed in experiments 1 and 2 . In contrast to the aftereffects in experiments 1 and 2, the aftereffects in experiment 3 were not induced by sensory differences between the adaptor stimuli, since these stimuli were physically identical.

Analysis for sensory aftereffects revealed negative results: values of $d^{\prime}$ did not vary significantly across the subjective adaptor conditions ( $t_{12}=0.42, P=0.7$; Fig. $\left.5 \mathrm{~A}\right)$. However, analysis for decisional aftereffects revealed significantly more negative $C$-values following adaptors that were judged as 'continuous' than following adaptors that were judged as 'discontinuous' $\left(t_{12}=3.35, P<0.006\right.$; Fig. $\left.5 \mathrm{~B}\right)$. This indicates that listeners adjusted their decision criterion depending on their previous judgment; they were more inclined to judge the target as 'continuous' when they had judged the preceding adaptor as 'continuous'. This contrasts with experiments 1 and 2, where listeners were more inclined to judge the target as 'continuous' following (soft) adaptors that they had judged mostly as 'discontinuous'.

The criterion shift was reflected in listeners' continuity rating data, showing that the interrupted target was judged as 'continuous' more often following reports of the adaptor as also 'continuous' than following reports of the same adaptor as 'discontinuous' $\left(t_{12}=2.76\right.$, $P<0.02$; see FA rates in Fig. $5 C$ ). This 'assimilative' aftereffect was observed also for the uninterrupted target $\left(t_{12}=2.94, P<0.02\right.$; see hit rates in Fig. 5D).

The assimilative aftereffects observed in experiment 3 differed from the aftereffects observed in experiments 1 and 2, which were contrastive in nature. Statistical group comparisons of experiment 1 $v s$. experiment 3 confirmed that the physically different adaptors induced significantly stronger aftereffects (defined as differences in $d^{\prime}$ and differences in $C$ across the adaptor conditions) than the physically identical adaptors (differences in $d^{\prime}: t_{25}=2.10, P<0.05$; differences in $\left.C: t_{25}=8.42, P<0.00000001\right)$. Thus, the stronger aftereffects
A
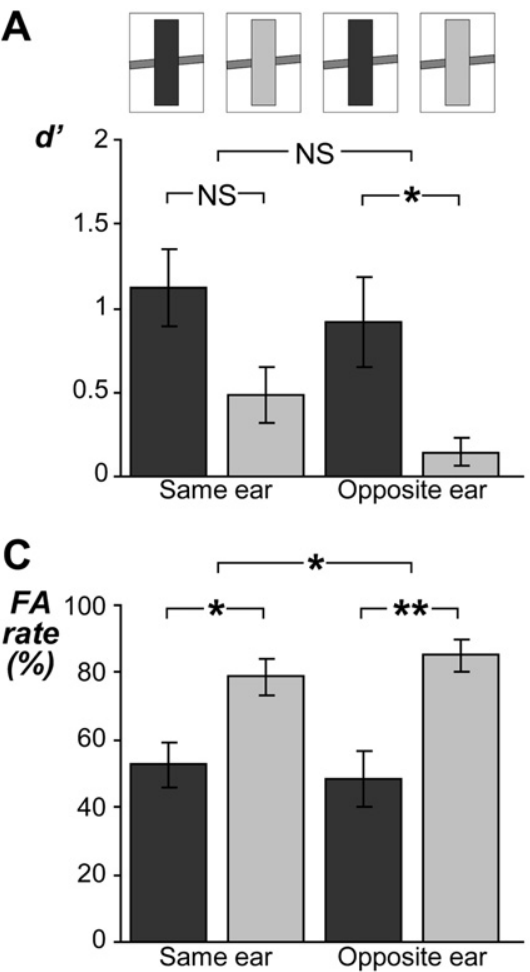

B

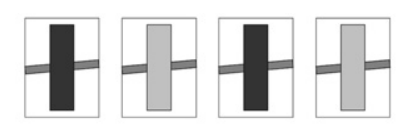

C
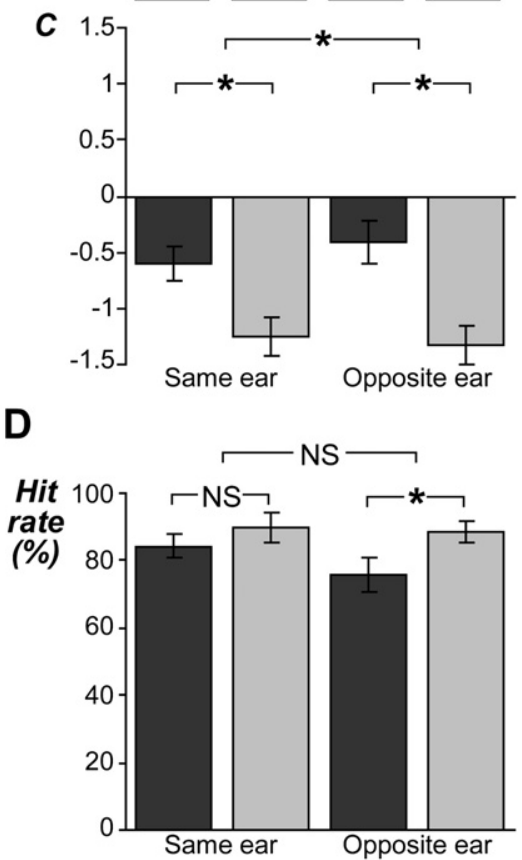

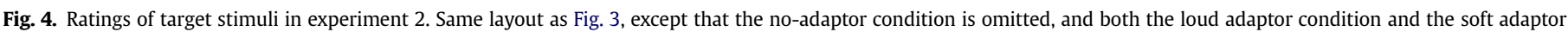

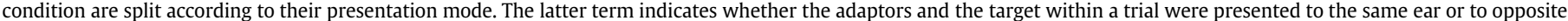

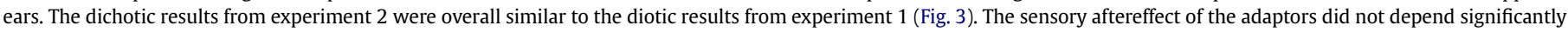

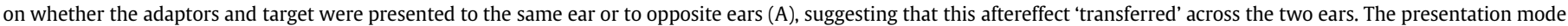

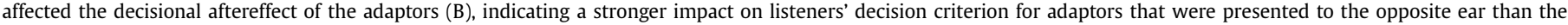
target. 

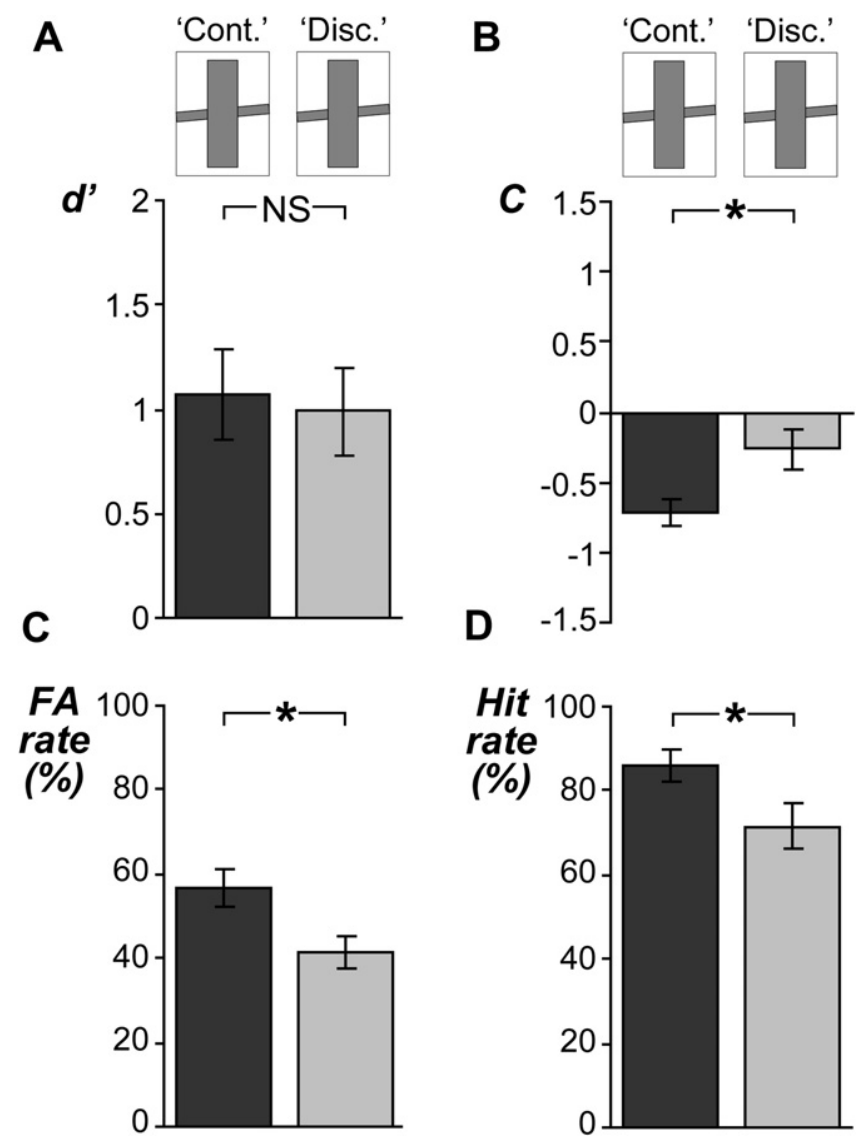

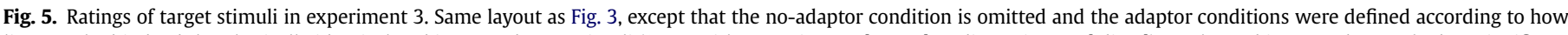

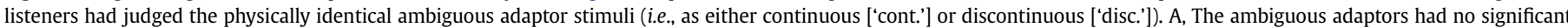

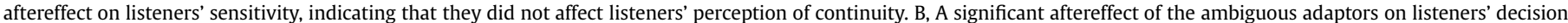

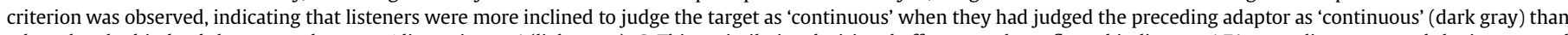

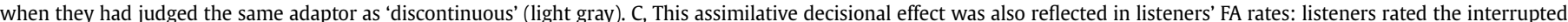

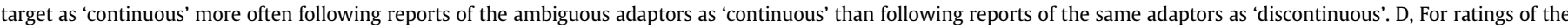

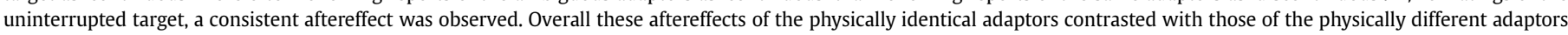
observed in experiments 1 and 2, indicating that the former were due to decisional factors rather than sensory factors (for details, see main text).

observed in experiments 1 and 2 could be ascribed to physical rather than subjective differences between the adaptor conditions.

The results reported above were based on a dataset in which the adaptor conditions were defined by listeners' judgments of the second adaptor that immediately preceded the target (see section 2.5). Additional analyses of another dataset comprising only trials on which listeners had given identical judgments for the first and the second adaptor provided slightly more significant statistical outcomes, despite being based on smaller numbers of trials.

\section{Discussion}

\subsection{Summary of results}

The results of this study demonstrate a contrastive aftereffect associated with the continuity illusion: Listeners were more likely to judge a physically discontinuous tone as continuing through noise when a preceding tone contained a clear gap, compared to when the preceding tone contained a gap that was masked by a loud noise. By analyzing the data within the framework of SDT, we could determine that this aftereffect reflects a genuine change in listeners' perception of continuity, in addition to a change in listeners' decision strategy (experiment 1 ). The results further indicate that the aftereffect 'transfers' across the two ears, i.e., it is observed even when the preceding tone and the present tone are presented to opposite ears (experiment 2). Finally, the results reveal that also physically identical auditory stimuli can induce an aftereffect, depending on whether these stimuli were judged as continuous or discontinuous (experiment 3 ). In contrast to the contrastive aftereffect observed in experiments 1 and 2 using physically different stimuli, this latter aftereffect is assimilative, and it affects listeners' decision strategy, rather than listeners' perception of continuity.

\subsection{Factors that potentially contributed to the observed aftereffects}

Two types of aftereffects have been identified in cognitive tasks, one based on sensory factors and one based on decisional factors (for review, see Jones et al., 2006). Sensory factors refer to the influence of a priorly experienced sensation on the perception or judgment of a current stimulus. A prime example of this is neural adaptation (or 'fatigue'), wherein the sensation evoked by a current stimulus is reduced when this stimulus is preceded by a similar one (e.g., Bartlett and Wang, 2005; Brosch and Schreiner, 1997; Ulanovsky et al., 2003, 2004; Werner-Reiss et al., 2006). Decisional factors refer to the influence of priorly made decisions (or categorizations) 
on the perception or judgment of a current stimulus. For example, when listeners are presented twice with the same stimulus, they may decide to give the same response to the second stimulus as they gave to the first stimulus (e.g., Verplanck et al., 1952).

A previous study that aimed at separating sensory and decisional factors has shown that sensory factors can induce contrastive aftereffects, whereas decisional factors may induce assimilative or contrastive aftereffects (Jones et al., 2006). Similar patterns have been observed in a variety of tasks focusing on sensory features in different modalities, including loudness or pitch (Jesteadt et al., 1977; Marks, 1993; Mori and Ward, 1995; Petzold, 1981), geometric size (Jones et al., 2006; Stewart et al., 2002), or taste intensity (Rankin and Marks, 1991; Schifferstein and Frijters, 1992), and they are consistent with our results on auditory continuity. The sensory factors have been interpreted as influencing sensory adaptation processes, or short-term memory traces of prior stimuli (Petzold, 1981), and they may operate prior to decisional processes (Marks, 1993). Decisional factors, on the other hand, have been interpreted as influencing relatively late cognitive processes (Marks, 1993) and they may operate on guessing strategies (Petzold, 1981; Ward and Lockhead, 1971) or representations of response categories (Treisman, 1984).

\subsection{Contrastive aftereffect of prior gaps on the continuity illusion}

The aftereffect on continuity illusions that was observed in experiments 1 and 2 could be induced by sensory factors or decisional factors. These two factors were correlated in experiments 1 and 2, so their effects cannot be easily disentangled in these experiments. However, the contribution of sensory factors in experiments 1 and 2 can be inferred, at least partially, by considering the contribution of these factors in experiment 3 . In contrast to experiments 1 and 2, sensory factors in experiment 3 were absent, since the adaptor stimulus remained physically constant. Thus, sensory factors could contribute in experiments 1 and 2, but not in experiment 3 , which may explain why a sensory aftereffect was observed in experiments 1 and 2, but not in experiment 3 . Based on these considerations, the sensory aftereffect observed in experiments 1 and 2 can be ascribed to sensory factors. The sensory properties of the adaptor that varied across the conditions in experiments 1 and 2 include the salience of the gap in the tone and the loudness of the noise (relative to that of the tone). The lack of a significant difference in sensitivity (as measured by $d^{\prime}$ ) following the no adaptor (baseline) condition versus the loud-noise condition indicates that the loudness of the noise was not a factor. In contrast, a significant aftereffect on sensitivity was observed that depended on the salience of the gap in the tone.

\subsection{Potential neural mechanisms for the contrastive aftereffect on the continuity illusion}

The contrastive aftereffect of prior gaps on the continuity illusion could originate in neurons that are sensitive to temporal gaps. Such 'gap detectors' are abundant in the central auditory system, including the primary auditory cortex (for reviews, see Phillips et al., 2002; Recanzone and Sutter, 2008), and neural responses to sound onsets/offsets have been associated with the continuity illusion (Heinrich et al., 2008; Husain et al., 2005; Petkov et al., 2007; Riecke et al., 2007, 2009a; Shahin et al., 2009). The relevance of neural gap detectors for the continuity illusion is consistent with psychophysical data indicating that the continuity illusion depends on listeners' failure to perceive gaps in a target sound (Bregman and Dannenbring, 1977). Our current finding that the presentation of interrupted tones in soft noise (i.e., sounds with clearly audible gaps) increases the likelihood of perceiving a subsequent interrupted tone as continuous could be due to the adaptation of such gap detectors in the auditory system. This explanation could be verified in the future, for example, by comparing the response of gap-sensitive auditory neurons to interrupted sounds that were presented after sounds containing either gaps or no gaps.

Although it is conceivable that the aftereffect observed in experiments 1 and 2 originates before the auditory cortex (e.g., at an earlier processing stage), our observation that it may transfer across the two ears (experiment 2) suggests that the aftereffect does not originate before the cochlear nuclei in the brainstem - the first stage along the ascending auditory pathway at which sensory input from the left and right ear is combined (for review, see Davis, 2005).

An interesting question is whether the suggested mechanism can also account for visual filling-in phenomena (Pessoa and De Weerd, 2003). Illusorily filled surfaces have been shown to evoke afterimages (Shimojo et al., 2001) and to influence subsequent visual discrimination thresholds even in the opposite eye (Morgan et al., 2007). Such aftereffects are thought to originate after binocular integration and to result from the adaptation of border representations in early visual cortex (for review, see Komatsu, 2006). Our results show some superficial similarities to these previous findings. However, more research is needed in order to draw conclusions about potentially analogous mechanisms in the auditory and visual systems (for similar discussions, see King and Nelken, 2009; Petkov and Sutter, 2010).

\subsection{Assimilative aftereffect of prior continuity reports on decision criteria}

The aftereffect observed in experiment 3 differed fundamentally from that observed in experiments 1 and 2: it could mainly be ascribed to decisional factors (instead of sensory factors), it was assimilative (instead of contrastive), and it only affected listeners' decision criterion (instead of listeners' decision criterion and continuity perception). A possible explanation for this stimulusindependent assimilative aftereffect is that listeners relaxed their decision criterion (i.e., they used a bias toward reporting continuity) following a report of continuity in order to respond consistently across presentations of similar stimuli (Shepard, 1957). Listeners seemed to follow this strategy especially in experiment 3, probably because successive stimuli were most similar in that experiment. On the other hand, in experiments 1 and 2, listeners showed clear contrastive changes in their decision criterion, probably because successive stimuli were more dissimilar in these experiments. These different observations are consistent with previous reports that the strength of assimilative decisional aftereffects may increase with the similarity of the adaptor and target stimuli, and that, when the adaptor and target differ greatly, the aftereffects can become contrastive (Jones and Sieck, 2003, 2006; Marks, 1993). Unlike the sensory aftereffect observed in experiments 1 and 2 , the decisional aftereffects observed in all three experiments may originate at a post-perceptual stage (Samuel, 1981) that could involve nonauditory cortical regions (for review on the neural basis of decision making, see Gold and Shadlen, 2007).

\subsection{Methodological considerations}

Because masked thresholds for tones in flat-spectrum noise tend to increase with frequency, the initial portion of the tone sweep (near $1 \mathrm{kHz}$ ) would have been more audible during noise than the final portion (near $3 \mathrm{kHz}$ ). However, this small difference unlikely affected our results, since the task required listeners to rate the entire stimulus rather than particular stimulus portions.

The pre-adaptors in experiment 3 were physically different; however, their aftereffects likely decayed before the target was presented more than $10 \mathrm{~s}$ later. This is supported by the results of 
experiment 1, which show that listeners' performance returned to chance level (i.e., to the non-adapted case) within $10 \mathrm{~s}$ of silence.

A different problem may arise when the listener's performance is at ceiling (i.e., FA rates and/or hit rates are equal or close to zero or one) since measures of sensitivity may become inaccurate (Brown and White, 2005). To address this potential issue in our study, we conducted supplemental statistical analyses in which we identified ceiling cases (for details, see Supplemental information). Exclusion of these cases and re-analysis of the remaining data revealed outcomes (see supplemental Figure S3) that were slightly less significant, but generally consistent with the results of experiments 1 and 3, indicating that ceiling cases, although present, constituted no major confound in our results. For experiment 2, several aftereffects did not reach significance (see supplemental Figure S3), which may be explained by insufficient statistical power due to more ceiling cases, suggesting that the sensory aftereffects observed in experiment 2 should be interpreted with some caution.

The validities of sensitivity and criterion measures utilized here rely on the assumption that listeners' internal noise contributed equally to the sensory representations of the different stimuli. This equal-variance Gaussian model has been shown to provide a good approximation to a large number of psychophysical data and is commonly used by many researchers (Wickens, 2002). It would be interesting to investigate in future studies whether this assumption also holds in the context of illusory phenomena such as the auditory continuity illusion. This would require detailed measurements of receiver operating characteristics using a rating paradigm and stimuli similar to those used here but with a larger number of SNRs.

\subsection{Previous studies of aftereffects on non-illusory auditory phenomena}

A series of adaptation studies on auditory streaming by Snyder and colleagues (2009a; 2008; 2009b) have shown that the frequency separation of two alternating sound streams may exert an aftereffect on subsequent streaming. More specifically, these results have demonstrated that prior streams with large frequency separation may decrease the likelihood that subsequent streams with ambiguous frequency separation are judged as segregated (Snyder et al., 2009a, 2008). It was found that such contrastive aftereffects may persist for approximately $13 \mathrm{~s}$. The observed aftereffect was relatively frequency-unspecific and auditoryspecific, since it could be induced by prior auditory streams of different frequencies, but not by visual streams (Snyder et al., 2009b). It was further found that changes in listeners' judgments of physically identical stimuli can induce an assimilative aftereffect on subsequent judgments of streaming.

Adaptation studies on speech have shown that the categorization of phonemes depends negatively on prior speech, including illusory speech (Samuel, 1997), and even nonspeech (Holt, 2005, 2006). Thus, these contrastive aftereffects may depend not only on linguistic or phonotactic probabilities of prior speech, but more generally on the spectral probabilities of prior auditory input (Holt, 2005). Consistently, it has been suggested that such an aftereffect may arise from adaptation at early sensory rather than lexical stages (Holt, 2006; Samuel, 1997). This idea is further supported by the observation that this aftereffect may arise even when listeners are not attending to the prior adaptor sounds (Samuel and Kat, 1998). However, it has been shown that the aftereffect of prior speech can be explained at least partially by changes in listeners' decision strategy (Diehl et al., 1978; Elman, 1979). In addition, it is likely that speech adaptation also involves adaptive changes in higher-level representations, given that the aftereffect influences only phonemes that belong to a well-established perceptual category (Aravamudhan et al., 2008).

These aftereffects on auditory streaming and phonemic categorization are qualitatively similar to the aftereffects on the continuity illusion observed in the current study, suggesting that a general auditory mechanism may be involved (Snyder et al., 2008). However, as indicated earlier (see section 4.2), such a mechanism may operate also in non-auditory modalities. The current results extend most of the above findings by showing that the contrastive aftereffects influence listeners' auditory perception (in this case, the perception of auditory continuity, as measured by changes in $d^{\prime}$ ) and listeners' decisions (as measured by changes in $C)$, whereas the assimilative aftereffects specially influence listeners' decisions. Presumably, the perceptual aftereffects arise from neural adaptation in sensory feature-specific circuits (in this case, auditory gap detectors), whereas the decisional aftereffects arise from strategy shifts at hierarchically higher, modalityunspecific processing stages.

\subsection{Conclusion}

The continuity illusion serves to reduce interference by extraneous sounds in natural scenes where multiple sounds often coincide. We propose that prior sounds recalibrate this illusion to different auditory scenes by adapting neural gap detectors in central neural circuits. Specifically, exposure to gaps may increase the likelihood that subsequent sounds appear more stable during interfering sounds. This recalibration of continuity hearing could serve to optimize perceptual stability according to the acoustic dynamics of the environment, which may be especially useful for situations in which interrupting sounds are unlikely to signal ecologically relevant events, such as in crowded scenes.

\section{Acknowledgment}

This work was supported by the Netherlands Organization for Scientific Research (NWO) Cognitie programma Grant 05104020. The authors thank Andrew Oxenham for useful discussions. Author CM is supported by an NIH grant (R01 DC007657).

\section{Appendix. Supplementary material}

The supplementary data associated with this article can be found in the on-line version at doi:10.1016/j.heares.2011.01.013.

\section{References}

Aravamudhan, R., Lotto, A.J., Hawks, J.W., 2008. Perceptual context effects of speech and nonspeech sounds: the role of auditory categories. J. Acoust. Soc. Am. 124 1695-1703.

Bartlett, E.L., Wang, X., 2005. Long-lasting modulation by stimulus context in primate auditory cortex. J. Neurophysiol. 94, 83-104.

Bashford Jr., J.A., Warren, R.M., 1987. Multiple phonemic restorations follow the rules for auditory induction. Percept Psychophys 42, 114-121.

Benjamini, Y., Hochberg, Y., 1995. Controlling the false discovery rate: a practical and powerful approach to multiple testing. J. R Stat. Soc. B57, 289-300.

Bennett, K.B., Parasuraman, R., Howard Jr., J.H., O’Toole, A.J., 1984. Auditory induction of discrete tones in signal detection tasks. Percept Psychophys 35 570-578.

Braaten, R.F., Leary, J.C., 1999. Temporal induction of missing Birdsong segments in European starlings. Psychol. Sci. 10, 162-166.

Bregman, A.S., 1978. Auditory streaming is cumulative. J. Exp. Psychol. Hum. Percept Perform. 4, 380-387.

Bregman, A.S., 1990. Auditory Scene Analysis: The Perceptual Organization of Sound. MIT Press, Cambridge.

Bregman, A.S., Dannenbring, G.L., 1977. Auditory continuity and amplitude edges. Can. J. Psychol. 31, 151-159.

Brosch, M., Schreiner, C.E., 1997. Time course of forward masking tuning curves in cat primary auditory cortex. J. Neurophysiol. 77, 923-943. 
Brown, G.S., White, K.G., 2005. The optimal correction for estimating extreme discriminability. Behav. Res. Methods 37, 436-449.

Ciocca, V., Bregman, A.S., 1987. Perceived continuity of gliding and steady-state tones through interrupting noise. Percept Psychophys 42, 476-484.

Condon, C.D., Weinberger, N.M., 1991. Habituation produces frequency-specific plasticity of receptive fields in the auditory cortex. Behav. Neurosci 105, 416-430.

Davis, K.A., 2005. Contralateral effects and binaural interactions in dorsal cochlear nucleus. J. Assoc. Res. Otolaryngol. 6, 280-296.

Diehl, R.L., Elman, J.L., McCusker, S.B., 1978. Contrast effects on stop consonant identification. J. Exp. Psychol. Hum. Percept Perform. 4, 599-609.

Eimas, P.D., Corbit, J.D., 1973. Selective adaptation of linguistic feature detectors. Cogn. Psychol. 4, 99-109.

Elman, J.L., 1979. Perceptual origins of the phoneme boundary effect and selective adaptation to speech: a signal detection theory analysis. J. Acoust. Soc. Am. 65, 190-207.

Fechner, G., 1960. Elements of Psychophysics Holt. Rinehart \& Winston, New York

Frissen, I., Vroomen, J., de Gelder, B., Bertelson, P., 2003. The aftereffects of ventriloquism: are they sound-frequency specific? Acta Psychol. (Amst) 113 315-327.

Frissen, I., Vroomen, J., de Gelder, B., Bertelson, P., 2005. The aftereffects of ventriloquism: generalization across sound-frequencies. Acta Psychol. (Amst) 118, 93-100.

Gold, J.I., Shadlen, M.N., 2007. The neural basis of decision making. Annu. Rev. Neurosci. 30, 535-574

Green, D.M., Swets, J.A., 1966. Signal Detection Theory and Psychophysics. Wiley, New York.

Green, G.G., Kay, R.H., 1974. Channels in the human auditory system concerned with the wave form of the modulation present in amplitude and frequency-modulated tones. J. Physiol. 241, 29P-30P.

Heinrich, A., Carlyon, R.P., Davis, M.H., Johnsrude, I.S., 2008. Illusory vowels resulting from perceptual continuity: a functional magnetic resonance imaging study. J. Cogn. Neurosci. 20, 1737-1752.

Holt, L.L., 2005. Temporally nonadjacent nonlinguistic sounds affect speech categorization. Psychol. Sci. 16, 305-312.

Holt, L.L., 2006. The mean matters: effects of statistically defined nonspeech spectra distributions on speech categorization. J. Acoust. Soc. Am. 120, 2801-2817.

Houtgast, T., 1972. Psychophysical evidence for lateral inhibition in hearing. J. Acoust. Soc. Am. 51, 1885-1894.

Husain, F.T., Lozito, T.P., Ulloa, A., Horwitz, B., 2005. Investigating the neural basis of the auditory continuity illusion. J. Cogn. Neurosci. 17, 1275-1292.

Jesteadt, W., Luce, R.D., Green, D.M., 1977. Sequential effects in judgments of loudness. J. Exp. Psychol. Hum. Percept Perform. 3, 92-104.

Jones, M., Sieck, W.R., 2003. Learning myopia: an adaptive recency effect in category learning. J. Exp. Psychol. Learn. Mem. Cogn. 29, 626-640.

Jones, M., Love, B.C., Maddox, W.T., 2006. Recency effects as a window to generalization: separating decisional and perceptual sequential effects in category learning. J. Exp. Psychol. Learn. Mem. Cogn. 32, 316-332.

King, A.J., Nelken, I., 2009. Unraveling the principles of auditory cortical processing: can we learn from the visual system? Nat. Neurosci. 12, 698-701.

Kluender, K.R., Jenison, R.L., 1992. Effects of glide slope, noise intensity, and noise duration on the extrapolation of FM glides through noise. Percept Psychophys $51,231-238$.

Komatsu, H., 2006. The neural mechanisms of perceptual filling-in. Nat. Rev. Neurosci. 7, 220-231.

Macmillan, N.A., Creelman, C.D., 1991. Detection Theory: A User's Guide. Cambridge UP, Cambridge.

Malone, B.J., Scott, B.H., Semple, M.N., 2002. Context-dependent adaptive coding of interaural phase disparity in the auditory cortex of awake macaques. J. Neurosci. 22, 4625-4638.

Mapes-Riordan, D., Yost, W.A., 1999. Loudness recalibration as a function of level J. Acoust. Soc. Am. 106, 3506-3511.

Marks, L.E., 1993. Contextual processing of multidimensional and unidimensional auditory stimuli. J. Exp. Psychol. Hum. Percept Perform. 19, 227-249.

Micheyl, C., Tian, B., Carlyon, R.P., Rauschecker, J.P., 2005. Perceptual organization of tone sequences in the auditory cortex of awake macaques. Neuron 48, 139-148.

Micheyl, C., Carlyon, R.P., Shtyrov, Y., Hauk, O., Dodson, T., Pullvermuller, F., 2003. The neurophysiological basis of the auditory continuity illusion: a mismatch negativity study. J. Cogn. Neurosci. 15, 747-758.

Miller, C.T., Dibble, E., Hauser, M.D., 2001. Amodal completion of acoustic signals by a nonhuman primate. Nat. Neurosci. 4, 783-784.

Miller, G.A., Licklider, J.C.R., 1950. The intelligibility of interrupted speech. J. Acoust Soc. Am. 22, 167-173.

Morgan, M.J., McEwan, W., Solomon, J., 2007. The lingering effects of an artificial blind spot. PLoS One 2, e256.

Mori, S., Ward, L.M., 1995. Pure feedback effects in absolute identification. Percept Psychophys 57, 1065-1079.

Pessoa, L., De Weerd, P., 2003. Filling-in: From Perceptual Completion to Cortica Reorganization. Oxford University Press, Oxford/New York.

Petkov, C.I., Sutter, M.L., 2010. Evolutionary conservation and neuronal mechanisms of auditory perceptual restoration. Hear Res.

Petkov, C.I., O'Connor, K.N., Sutter, M.L., 2003. Illusory sound perception in macaque monkeys. J. Neurosci. 23, 9155-9161.

Petkov, C.I., O'Connor, K.N., Sutter, M.L., 2007. Encoding of illusory continuity in primary auditory cortex. Neuron $54,153-165$
Petzold, P., 1981. Distance effects on sequential dependencies in categorical judgments. J. Exp. Psychol. Hum. Percept Perform. 7, 1371-1385.

Phillips, D.P., Hall, S.E., 2005. Psychophysical evidence for adaptation of central auditory processors for interaural differences in time and level. Hear Res. 202, 188-199.

Phillips, D.P., Hall, S.E., Boehnke, S.E., 2002. Central auditory onset responses, and temporal asymmetries in auditory perception. Hear Res. 167, 192-205.

Rankin, K.M., Marks, L.E., 1991. Differential context effects in taste perception. Chem. Senses 16, 617-629.

Recanzone, G.H., Sutter, M.L., 2008. The biological basis of audition. Annu. Rev. Psychol. 59, 119-142.

Riecke, L., van Opstal, A.J., Goebel, R., Formisano, E., 2007. Hearing illusory sounds in noise: sensory-perceptual transformations in primary auditory cortex. J. Neurosci. 27, 12684-12689.

Riecke, L., Esposito, F., Bonte, M., Formisano, E., 2009a. Hearing illusory sounds in noise: the timing of sensory-perceptual transformations in auditory cortex. Neuron 64, 550-561.

Riecke, L., Mendelsohn, D., Schreiner, C., Formisano, E., 2009b. The continuity illusion adapts to the auditory scene. Hear Res. 247, 71-77.

Samuel, A.G., 1981. Phonemic restoration: insights from a new methodology. J. Exp. Psychol 110, 474-494.

Samuel, A.G., 1997. Lexical activation produces potent phonemic percepts. Cogn. Psychol. 32, 97-127.

Samuel, A.G., Kat, D., 1998. Adaptation is automatic. Percept Psychophys 60, 503-510.

Sawusch, J.R., Jusczyk, P., 1981. Adaptation and contrast in the perception of voicing. J. Exp. Psychol. Hum. Percept Perform. 7, 408-421.

Scharf, B., Buus, S., Nieder, B., 2002. Loudness enhancement: induced loudness reduction in disguise? (L). J. Acoust. Soc. Am. 112, 807-810.

Schellenberg, E.G., Trehub, S.E., 1994. Frequency ratios and the discrimination of pure tone sequences. Percept Psychophys 56, 472-478.

Schifferstein, H.N., Frijters, J.E., 1992. Contextual and sequential effects on judgments of sweetness intensity. Percept Psychophys 52, 243-255.

Schreiner, C., 1980. Encoding of alternating acoustical signals in the medial geniculate body of guinea pigs. Hear Res. 3, 265-278.

Schweinberger, S.R., Casper, C., Hauthal, N., Kaufmann, J.M., Kawahara, H., Kloth, N., Robertson, D.M., Simpson, A.P., Zaske, R., 2008. Auditory adaptation in voice perception. Curr. Biol. 18, 684-688.

Seeba, F., Klump, G.M., 2009. Stimulus familiarity affects perceptual restoration in the European starling (Sturnus vulgaris). PLoS One 4, e5974.

Sekuler, R., Blake, R., 1994. Perception. McGraw-Hill, New York.

Shahin, A.J., Bishop, C.W., Miller, L.M., 2009. Neural mechanisms for illusory fillingin of degraded speech. Neuroimage 44, 1133-1143.

Shepard, R.N., 1957. Stimulus and response generalization: a stochastic model relating generalization to distance in psychological space. Psychometrika 22, $325-345$.

Shimojo, S., Kamitani, Y., Nishida, S., 2001. Afterimage of perceptually filled-in surface. Science 293, 1677-1680.

Simon, H.J., Studdert-Kennedy, M., 1978. Selective anchoring and adaptation of phonetic and nonphonetic continua. J. Acoust. Soc. Am. 64, 1338-1357.

Sivonen, P., Maess, B., Lattner, S., Friederici, A.D., 2006. Phonemic restoration in a sentence context: evidence from early and late ERP effects. Brain Res. 1121, 177-189.

Snyder, J.S., Carter, O.L., Hannon, E.E., Alain, C., 2009a. Adaptation reveals multiple levels of representation in auditory stream segregation. J. Exp. Psychol. Hum. Percept Perform. 35, 1232-1244.

Snyder, J.S., Carter, O.L., Lee, S.K., Hannon, E.E., Alain, C., 2008. Effects of context on auditory stream segregation. J. Exp. Psychol. Hum. Percept Perform. 34, 1007-1016.

Snyder, J.S., Holder, W.T., Weintraub, D.M., Carter, O.L., Alain, C., 2009b. Effects of prior stimulus and prior perception on neural correlates of auditory stream segregation. Psychophysiology 46, 1208-1215.

Stewart, N., Brown, G.D., Chater, N., 2002. Sequence effects in categorization of simple perceptual stimuli. J. Exp. Psychol. Learn. Mem. Cogn. 28, 3-11.

Sugita, Y., 1997. Neuronal correlates of auditory induction in the cat cortex. Neuroreport 8, 1155-1159.

Tansley, B.W., Suffield, J.B., 1983. Time course of adaptation and recovery of channels selectively sensitive to frequency and amplitude modulation. J. Acoust. Soc. Am. 74, 765-775.

Thurlow, W., 1957. An auditory figure-ground effect. Am. J. Psychol. 70, 653-654.

Treisman, M., 1984. A theory of criterion setting: an alternative to the attention band and response ratio hypotheses in magnitude estimation and crossmodality matching. J. Exp. Psychol 113, 443-463.

Ulanovsky, N., Las, L., Nelken, I., 2003. Processing of low-probability sounds by cortical neurons. Nat. Neurosci. 6, 391-398.

Ulanovsky, N., Las, L., Farkas, D., Nelken, I., 2004. Multiple time scales of adaptation in auditory cortex neurons. J. Neurosci. 24, 10440-10453.

Verplanck, W.S., Collier, G.H., Cotton, J.W., 1952. Nonindependence of successive responses in measurements of the visual threshold. J. Exp. Psychol. 44, $273-282$.

Verschuure, J., Brocaar, M.P., 1983. Intelligibility of interrupted meaningful and nonsense speech with and without intervening noise. Percept Psychophys 33, $232-240$.

Wakefield, G.H., Viemeister, N.F., 1984. Selective adaptation to linear frequencymodulated sweeps: evidence for direction-specific FM channels? J. Acoust. Soc. Am. 75, 1588-1592. 
Ward, L.M., Lockhead, G.R., 1971. Response system processes in absolute judgment. Percept Psychophys 9, 73-78.

Warren, R.M., 1970. Perceptual restoration of missing speech sounds. Science 167, 392-393.

Warren, R.M., 1999. Auditory Perception: A New Analysis and Synthesis. Cambridge University Press, Cambridge, UK.
Warren, R.M., Obusek, C.J., Ackroff, J.M., 1972. Auditory induction: perceptual synthesis of absent sounds. Science 176, 1149-1151.

Werner-Reiss, U., Porter, K.K., Underhill, A.M., Groh, J.M., 2006. Long lasting attenuation by prior sounds in auditory cortex of awake primates. Exp. Brain Res. 168, 272-276. Wickens, T.D., 2002. Elementary Signal Detection Theory. Oxford University Press, New York. 